\title{
ESTRATEGIAS PARA LA AUTOSOSTENIBILIDAD DEL PATRIMONIO EN EL MEDIO RURAL
}

\author{
STRATEGIES FOR SELF SUSTAINABILITY OF \\ HERITAGE IN THE RURAL ENVIRONMENT
}

Javier Fernández Ortea

Proyecto Arqueológico Caraca, España

\section{RESUMEN}

El patrimonio histórico español se ubica predominantemente en áreas rurales, sin embargo, no ha sido objeto de la misma atención que su vecino urbano. Potenciar el legado arqueológico, histórico, gastronómico y etnológico es potenciar el ámbito rural. La nueva profesión del gestor cultural debe crear estrategias activas que conecten territorio, patrimonio y visitantes. A partir del Plan de Gestión se delinean políticas activas sobre nuestros recursos y sus destinatarios, conservando y haciendo sostenible la herencia recibida.

Palabras clave: Gestión del patrimonio, rural, turismo cultural, recursos históricos.

\begin{abstract}
The Spanish heritage is located predominantly in rural areas, however, it has not been subject to the same attention as its urban neighbor. Enhancing the archaeological, historical, culinary, ethnological legacy is to boost rural areas. The new profession of cultural manager must create active strategies that connect the territory, heritage and visitors. The Management Plan is the starting point for the outlining of active policies on the resources and its recipients for the conservation and sustainable use of heritage.
\end{abstract}

Keywords: Heritage management, rural, cultural tourism, historic resources.

Este es un artículo Open Access bajo la licencia Creative Commons Atribución-NoComercial-Compartirlgual 4.0

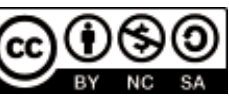




\section{¿Qué es patrimonio?}

Para comenzar la argumentación del presente artículo comenzaremos con acercarnos al concepto de patrimonio, protagonista y sujeto de este ensayo. Derivado del latín patrimonium, se entiende etimológicamente como lo heredado de los antepasados. El título I de la Ley de Patrimonio Histórico Español 16/85 señala:

Integran el Patrimonio Histórico Español los inmuebles y objetos muebles de interés artístico, histórico, paleontológico, arqueológico, etnográfico, científico o técnico. También forman parte del mismo el patrimonio documental y bibliográfico, los yacimientos y zonas arqueológicas, así como los sitios naturales, jardines y parques, que tengan valor artístico, histórico y antropológico.

Asimismo añade, forma parte del patrimonio histórico el patrimonio inmaterial conforme a la legislación propia. Legalmente el concepto sigue siendo difuso ya que la categoría valor es ambigua, pudiendo aludir a cuestiones económicas, afectivas, identitarias, algo que puede ser valioso para una persona puede no serlo para otra. La legislación patrimonial de Andalucía indica que «constituye la expresión relevante de la identidad del pueblo andaluz, testimonio de la trayectoria histórica de Andalucía y manifestación de la riqueza y diversidad cultural». Continúa el preámbulo de la Ley 14/2007 con una categoría clave, el sentimiento de aprecio, con que es envestido el patrimonio por parte de los ciudadanos. La premisa inicial de requerirse una antigüedad o relevancia artística va diluyéndose en favor de una significación que no tiene porqué ser histórica o estética, sino por su valor como manifestación de la actividad humana en general, aunque sea muy reciente (Prats, 1997). Esta tendencia queda confirmada en la propia legislación estatal al referirse a las colecciones de los museos como «de valor histórico, artístico, científico y técnico o de cualquier otra naturaleza cultural» (Tít. 7, Cap. II, Art. 59.3).

En conclusión, todo es susceptible de ser patrimonializado, la condición es que tenga una consideración relevante por parte de la comunidad, positiva o negativa. Elementos cargados de afectividad como museos, archivos, monumentos, pero también cárceles, centros de confinamiento, muros fronterizos, carteles publicitarios. El patrimonio etnológico, gastronómico, cinematográfico, musical, literario son solo algunos ejemplos que pueden ser instrumentalizados como recurso turístico.

\section{¿Qué es rural?}

Si acudimos al Diccionario de la Lengua Española (DLE), encontramos que lo rural es lo perteneciente al campo. La Organización para la Cooperación y el Desarrollo Económicos - OCDE (1988), emplea la palabra rural para territorios con débil densidad de población y con una actividad económica diversa, relativamente independiente de la influencia directa de las zonas metropolitanas. Comprende las tres cuartas partes del territorio y más de la mitad de la población de los países miembros de esta organización. En España, el Instituto Nacional de Estadística utiliza el término municipios rurales para aquellas entidades que tengan menos de 2000 habitantes. Por su parte, la Ley 45/2007, de 13 de diciembre, para el desarrollo sostenible del medio rural, en su Art. 3 acerca del medio rural dice que es «el espacio geográfico formado por la agregación de municipios o entidades locales menores definido por las administraciones competentes que posean una población inferior a 30000 
habitantes y una densidad inferior a los 100 habitantes por $\mathrm{km}^{2} »$. El predominio del sector productivo primario ha sido también herramienta para definir el concepto de ruralidad. Como podrá constatarse, demografía y actividad económica no han sido suficientes para delimitar la frontera entre lo rural y lo urbano. Es más, la tradicional dicotomía campo/ciudad, defendida desde 1929 como un continuo, es hoy superada con la introducción de las Tecnologías de la Información y la Comunicación - TIC (Sancho \& Reinoso, 2012, p. 601) .

El laxo concepto rural tiene un contexto de naturaleza inherente, sin embargo, con la globalización e internet es cada vez más próximo al mundo urbano.

\section{Turismo rural}

Traverso define el turismo rural como «la actividad turística de implantación sostenible en el medio rural (1996, p. 38). Se trata de un sector en progresivo crecimiento paralelamente al estancamiento del modelo de Sol y playa. El agotamiento de la oferta anterior ha empujado la búsqueda y afianzamiento de otros mercados de índole cultural y/o paisajística.

Una de los principales atractivos o fortalezas para la inversión en el sector del turismo rural es su resistencia a la estacionalidad. Comparativamente con el turismo de Sol y playa, vinculado al verano o al menos a períodos estivales, el turismo cultural tiene la capacidad de ser requerido todo el año. En cualquier caso, la demanda dependerá del tiempo libre disponible, especialmente fines de semana puentes, Semana Santa. Esto supone una ventaja competitiva importante ya que podrán ofrecerse servicios o productos de temporada que incentiven la visita.

Atendiendo el Informe de hábitos turísticos de los residentes en España (2007), encontramos estadísticas que invitan al optimismo: 56.2\% de los individuos residentes en España realizan alguna vez una excursión; $34.2 \%$ realiza viajes de fin de semana y dentro de esa porción $69 \%$ lo hace en todas las épocas del año. Por último, 25. 4\% tiene como principal motivación para viajar, los destinos culturales, siendo 34\% en Madrid.

El turismo rural podría agruparse en tres grandes líneas: turismo de relax, turismo activo y turismo familiar. El primero de ellos nació como consecuencia de la demanda de las grandes urbes por tener un espacio de desconexión y descanso. En esta línea se cuentan numerosas casas rurales, centros termales y alojamientos de toda índole. En muchos casos el patrimonio histórico se benefició de ello con la iniciativa estatal de los Paradores Nacionales o la marca Castilla Termal, con balnearios en edificios históricos. Otras iniciativas privadas han recuperado molinos industriales, masias e incluso hórreos para dar cobijo al visitante. De este modo se ha cumplido la tónica de que el valor de uso previene la ruina y garantiza la conservación. Con relación al turismo activo, han proliferado empresas que combinan naturaleza y arqueología en rutas senderistas de calidad. Este es un campo que aún tiene mucho margen de crecimiento, especialmente en la oferta de servicios activos y deportivos con carácter cultural en los propios espacios históricos. Por último, el turismo familiar, ya sea pernoctando en alojamientos privados (preferencia del 48\%) o de familiares y amigos (36\%), busca actividades para hacer juntos con afán recreativo y/o educativo. No debe minusvalorarse el carácter afectivo del destino (por razones familiares, orígenes, etc.) ni tampoco la segunda vivienda como recurso (20.1\%). 
La gran ventaja del patrimonio cultural es su carácter ecléctico, pudiendo ser combinado tanto con actividades deportivas, gastronómicas, musicales. Las actividades deportivas comienzan su alianza con el patrimonio histórico en nuestro país, visible en el buceo, la espeleología o el combate medieval; los acercamientos aún son tímidos. La suma de patrimonios sin duda enriquece la experiencia del visitante y lo inserta en el contexto regional de manera más efectiva.

\section{Turismo arqueológico}

El turismo motivado por razones culturales y/o educativas hunde sus raíces en el llamado Gran Tour de los siglos XVII y XVIII como complemento formativo de las elites (Muñoz, 2005). Estos fueron desplazamientos planificados como un aprendizaje. Existían anteriormente viajes de carácter cultural, caso de las peregrinaciones religiosas. Sin pretender desgranar el origen de estas corrientes, sí podemos afirmar su carácter pretérito. Por tanto, el patrimonio histórico ha sido fuente turística permanente antiguamente, el patrimonio arqueológico es un fenómeno reciente. Esto es debido a una razón muy sencilla, se encontraban enterrados hasta fechas recientes. La investigación arqueológica y su método es quien define legalmente qué es patrimonio arqueológico, «los bienes muebles e inmuebles de carácter histórico, susceptibles de ser estudiados con metodología arqueológica» (Art. 40.1 Ley 16/85 de PHE). Es por ello que para contar con un recurso turístico de interés arqueológico es necesaria una inversión previa en investigación, consolidación y difusión. La situación real es que, tal y como apuntan Elena Pérez y María Esther Chávez para el caso canario, «en la mayoría no se hace una difusión que atraiga a visitantes e incluso algunas han sufrido ya su degradación y están amenazadas de desaparecer por completo» (2012, p. 1727). Esta situación es especialmente dañina con la finalización de los trabajos de investigación científica.

Una de las grandes cualidades del patrimonio arqueológico es su variada naturaleza; desde pinturas rupestres, castros, ciudades romanas, complejos mineros o fortificaciones militares, por citar algunos. La administración ha pretendido incentivar su visita mediante rutas históricas como la ruta del Ibers, el Frente del agua, ruta de las Villas romanas de Palencia. El problema de base ha sido que tras una inversión en investigación, señalética e infraestructura no se corresponde un seguimiento en mantenimiento, menos aún en promoción. Valga como ejemplo, en este sentido, los problemas que amenazaron el cierre de conjuntos punteros como Segóbriga o Itálica, el primero por un déficit presupuestario y el segundo por falta de personal. Otro yacimiento señero como Numancia sufrió las críticas de los turistas ante la escasez de medios para paliar el crecimiento de la maleza, entre otros inconvenientes (véase referencias de prensa). Podrá aventurar el lector que si estos problemas se dan en los centros «estrella» la situación en el resto de enclaves menores no es precisamente mejor. La situación en los museos es pareja, valga como ejemplo el cierre indefinido del museo arqueológico de Granada, el cierre del Museo de Historia de Madrid, por no renovar al personal o la clausura de numerosas salas por la misma razón en el Museo Nacional de Cerámica de Valencia.

Los crónicos problemas que atenazan al patrimonio han hecho que algunos autores asuman que «es un reducto inexpugnable, por antieconómico, difícilmente vendible y concentrador de sensibilidades sociales muy agudas» (López \& Tudanca, 2006, p. 25). Jordi Juan Tresserres, presidente de Red de Patrimonio, Turismo y Desarrollo Sostenible (IBERTUR), en su entrevista en La Vanguardia, afirma que el patrimonio arqueológico 
español tiene un gran potencial pero que aún es un gran desconocido por el público. Las cifras desde luego apuntan interés por parte del turista. El Museo Arqueológico Nacional es de lejos el más visitado de sus homónimos dependientes del Ministerio de Cultura con 556044 visitantes en 2015. Los números respecto a los yacimientos son poco transparentes ya que no existen bases de datos accesibles o fiables. Si consideramos válidas las cifras aparecidas en prensa podemos argumentar los 68692 visitantes de las Médulas (León) en 2013; 45930 la villa de la Olmeda (Palencia) en 2015; 49317 de Segóbriga (Cuenca) en 2015. Un volumen notable como para ignorar su relevancia.

La diferencia más notable entre los yacimientos arqueológicos -salvo cuevas y recintos cerrados- respecto del patrimonio histórico inmueble es el carácter abierto, al aire libre. Esta es una diferencia que repercutirá en la presencia de turismo en función de la climatología.

Insertos en el territorio, los yacimientos arqueológicos son recursos turísticos rurales por antonomasia. Por tanto, potenciar la gestión de espacios arqueológicos es invertir en desarrollo rural en la esfera económica, social y mediática. Cabe aludir su interés en la generación de empleo directo e indirecto, creando oportunidades y reforzando la identidad y autoestima local.

En conclusión, queda pendiente la turistificación de gran parte del patrimonio, sea de naturaleza arqueológica, histórica, etnológica o de otra índole cultural, convirtiéndose en motor de desarrollo regional (Hiernaux, 2011, p. 6). Como reflexión, para hacer del patrimonio un acicate debe tener las herramientas adecuadas, especialmente el marketing, un concepto que parece sacrílego en este ámbito pero que en museos es ya habitual. No se puede pretender que el legado histórico sea la llave del desarrollo sin hacerlo competitivo en la economía de mercado.

\section{Plan de gestión}

En la gestión del patrimonio se suceden las siguientes fases; conocer, planificar, controlar y difundir (Querol, 2010, p. 51). Nos ocuparemos de las dos primeras como carácter previo del que se ocupa el Plan de Gestión.

En esta tesis debe elaborarse un marco de actuación teórico basado en una reflexión profunda a pie de campo que llamaremos Plan de gestión. Este documento será el escrito de referencia al que acudir para resolver dudas o elaborar nuevas estrategias. Es una compilación de datos, actores principales y recursos del entorno, es el territorio. Conocer el entorno nos permitirá conocer nuestras ventajas e inconvenientes.

La planificación es indispensable para alcanzar no solo un modelo de gestión sostenible sino para proteger nuestros recursos, máxima prioridad inexcusable. Este aspecto es una peculiaridad de la administración de espacios históricos. Según García (2012):

Para la industria turística, evidentemente, la tutela no es la prioridad. Entiende que hacer turismo es solo cuestión de promoción y no de planificación. No se plantea, por ejemplo, algo tan importante como evaluar lo que llamamos la capacidad de carga y el umbral de tolerancia que tiene un lugar, sus edificios, y su patrimonio en general, ni analiza el impacto positivo o negativo que puede significar el turismo. (p. 138) 
El Plan de gestión es la herramienta de planificación por definición. Se trata de un documento vivo, en constante mutación, ya que el entorno, la legislación o la tecnología disponible es cambiante. Si este documento es fósil pierde su función.

No vamos a describir nuestro modelo de Plan de gestión, ya publicado con anterioridad, por lo que nos limitaremos a citar la importancia de definir los siguientes puntos: objetivos, tarjet, plan de marketing, presupuestos, actividades previstas, infraestructura, competencia, modelo de gestión, plan de comunicación e impacto de la acción. Del mismo modo recomendamos el análisis interno mediante el uso del DAFO y el Balance Score Card - BSC (Fernández, 2017).

En la actualidad apenas existen planes de gestión per se, se redactan planes directores, con un cariz de interés científico aunque empiezan a tener una tímida preocupación por la sostenibilidad económica (Véase el Plan director del conjunto arqueológico de Carmona y Plan director del conjunto arqueológico de Itálica).

\section{El papel del gestor cultural}

La incipiente figura del gestor cultural es muy reciente en el ámbito del patrimonio histórico, siendo privativa de grandes instituciones museísticas con amplios recursos humanos. Esto se debe al dominio de los actores públicos en el sector cultural. En contraposición, el sector turístico se nutre principalmente de agentes provenientes del ámbito privado (Velasco, 2013). La necesidad de turistificar el patrimonio como vía de crear riqueza impuso que se empezase a hablar de industrias culturales. Industria cultural es «cualquier entidad con la misión de crear, producir y distribuir eventos, bienes, productos y servicios culturales» (Casacuberta, 2008, p. 14). En esta tarea el gestor cultural debe actuar de mediador entre la fuente de conocimiento y la economía de mercado. Para ello, será necesario tener formación humanística y en técnicas de marketing, pero especialmente experiencia y práctica para poder adecuarse a un contexto en permanente cambio (Asociación de profesionales de la gestión cultural de Catalunya, 2011).

La profesión del gestor cultural requiere autonomía de acción para su ejercicio pero dicha libertad está supeditada a resultados (Martinell, 2007, p. 12). La presencia de este perfil será cada vez más demandada ya que la tendencia en políticas de apoyo y subvenciones es hacia la incorporación de indicadores de rentabilidad económica y colaboración con el sector privado. Desde la mayoría de «organismos públicos se trabaja para diseñar nuevos sistemas de financiación que no pasen por las subvenciones a fondo perdido», razón que fortalece la necesidad del gestor cultural para conseguir la sostenibilidad (Rowan, 2010, p. 87).

El gestor cultural debe ser el responsable de la planificación, ejecución y evaluación de las estrategias de difusión del bien patrimonial, atendiendo a su doble naturaleza como recurso y como derecho. Los profesionales de la cultura, inmersos en un continuo proceso de innovación, son «productores, diseñadores, vendedores y promotores, todo a la vez» (Rowan, 2010, p. 41). Una de las funciones principales es su papel de comunicador, ejerciendo también de community manager en las redes sociales. Será responsable de introducir información, crear una comunidad y lanzar campañas temporales. Este canal, aún no disponible en muchas entidades patrimoniales, es un medio perfecto para alcanzar mayores audiencias, interactuar con el usuario, crear prescriptores y fidelizar visitantes. Esto significa superar el paradigma unidireccional, apostando por el feedback. 
En el campo arqueológico puede existir la dualidad e incluso la rivalidad entre la esfera de investigación y la de gestión. Esto se debe a que cada parcela primará sus objetivos, el conocimiento o la conservación, respectivamente (Criado-Boado, 1996). Sin embargo, la cooperación es irrenunciable, se requiere el saber científico para su interpretación posterior y la adecuada gestión de los recursos repercutirá en vías de financiación para la investigación. Desde este artículo abogamos por un equipo único con dos figuras responsables de cada ámbito.

\section{Herramientas del gestor cultural para la sostenibilidad}

Una vez redactado un completo Plan de gestión que contemple los nichos de mercado a los que debemos dirigirnos comenzará la fase de ejecución de estrategias activas de captación de visitantes. En nuestra experiencia de gestión los seis factores más determinantes en la atracción de visitantes a lugares patrimoniales son:

1. Estacionalidad / climatología

2. Infraestructura y servicios

3. Monumentalidad / singularidad

4. Vías de comunicación / acceso

5. Proximidad a otros recursos o urbes

6. Repercusión mediática, simbólica o científica

Estos elementos deben ser profundamente analizados para poder revertir o aminorar los efectos negativos y potenciar los positivos. Todos los factores, aunque parezcan irreversibles, tienen alguna vía de ser solucionados. Por ejemplo, en el caso de la climatología, a priori una causa con el que no se puede luchar, podemos ofrecer servicios o productos específicos de temporada que permitan reducir el impacto negativo de una condición adversa.

Estrategias activas son el conjunto de acciones encaminadas a obtener unos resultados cuantificables sobre un sujeto particular. Distinguiremos dos tipos en función del destinatario: el bien cultural y el visitante. Las estrategias activas sobre el bien cultural pretenden mejorar la percepción y prestaciones de nuestro recurso patrimonial de cara al visitante. Proponemos seis campos (Tabla 1).

Tabla 1

Estrategia activa sobre el bien cultural

\begin{tabular}{ccc}
\hline $\begin{array}{c}\text { Creación de productos } \\
\text { innovadores }\end{array}$ & $\begin{array}{c}\text { Plan } \\
\text { multiusos }\end{array}$ & $\begin{array}{c}\text { Organización de } \\
\text { eventos }\end{array}$ \\
\hline Inversión con retorno & Combinar recursos & Merchandise y DOC \\
\hline Fuente y elaboración propia &
\end{tabular}


La creación de productos innovadores debe ser una constante en el ámbito de la gestión del patrimonio, evitando la rutina en el visitante y potenciando la fidelización. Las preferencias de los turistas tienden hacia la demanda de servicios más heterogéneos y una mayor sensibilidad a consumos experienciales que complementen otro tipo de actividades tradicionales (Sostenuto, 2012).

Debe planificarse un plan multiusos de las instalaciones que atienda las distintas necesidades del visitante y el recurso turístico. Es importante contar con planos profesionales de la infraestructura disponible a nivel de edificios, instalación eléctrica, agua, calefacción, señalética y demás elementos que sean imprescindibles para poder llevar a cabo el uso multidisciplinar de un espacio. Esto es irrenunciable, tanto a nivel de planificación como a nivel legal, para poder solicitar las licencias prescriptivas en caso de desear enfocar una instalación para un uso distinto al meramente expositivo (tienda, cafetería, eventos, etc.). El carácter abierto y ecléctico de un centro permite cumplir el Art. 44 de la Constitución -derecho a la cultura- además de brindar un legado histórico antes vetado a los artistas, profesionales e investigadores; se trata de un modelo más democrático y participativo del pasado. En línea con el anterior punto, la organización de eventos de carácter educativo, lúdico o social hacen llegar a mayores capas de la sociedad nuestro producto, el patrimonio. Lo hacen sentir cercano, dejando atrás la idea de santuario inmaculado del origen de los museos.

La inversión con retorno se refiere a contabilizar el reintegro del gasto ejercido para llevar a cabo una acción o adquisición. Si nuestro interés es hacer de un espacio deficitario un lugar rentable, o al menos sostenible, no podemos seguir pensando en presupuestos con inversiones a fondo perdido. De este modo se calculan qué gastos son necesarios y viables y cuáles no podemos afrontar por ser claramente antieconómicos. Una política que cualquier empresa entiende como básica no lo es tanto en el mundo de la cultura aún. Entender que la cultura es un derecho y una necesidad no tiene porqué estar siempre en conflicto con entender la lógica de mercado coste/beneficio. Dos ejemplos personales en esta línea fueron la evaluación previa que hicimos con la introducción de electricidad en el monasterio de Monsalud, lo cual nos permitió realizar actividades nocturnas y la introducción de MP3 como sistema de audio guías en Ercávica. Sendas inversiones, variables en riesgo y en tiempo de amortización, fueron objeto de valoración y finalmente ambas fueron rentables.

Combinar recursos patrimoniales supone enriquecer nuestra oferta, especialmente si armonizamos tres factores decisivo: vivencial, emocional y físico (Organización Mundial del Turismo, 2013). En nuestra experiencia ha sido un éxito la inclusión del patrimonio gastronómico -garum y vino mulsum- como añadido que ilustre la cultura romana. La degustación de vino según las prescripciones de Columella en un peristilo del siglo I d. C. mientras se divisan las Perseidas es un conjunto integral que encaja y evoca. Podría sumarse patrimonio musical, etnológico, artístico, deportivo, enriqueciendo la actividad. Debemos potenciar nuestros beneficios como enclaves rurales tales como la disponibilidad de espacio, naturaleza, fauna, botánica, ornitología, escasa contaminación lumínica, tranquilidad. Un caso representativo es el taller de etnobotánica de Recópolis «Natura», acercándonos a las plantas que servían para hacer vidrio, encender las lámparas de aceite o perfumar el palacio de la ciudad.

La última estrategia activa sobre el recurso consiste en el diseño de una gama de productos corporativos o de merchandise propio. Para ello será necesario un logo atractivo que conecte el componente emotivo que despierta el patrimonio con el gusto del visitante. Lo más interesante de ello es que con la adquisición de un 
objeto con nuestra firma su portador se convierte en un cartel publicitario de nuestra existencia, alcanzando a potenciales visitantes. Al merchandise debe sumarse la presencia de productos Denominación de Origen Controlada (DOC), de este modo el turismo potencia también la industria y artesanía regional. El visitante puede adquirir productos de calidad contrastada y originales, cualidad muy valorada en un mundo globalizado. Si se desea pueden añadirse artículos temáticos afines al recurso patrimonial, reproducciones arqueológicas, libros, fotografías, posters, imanes, etc.

El segundo foco es la estrategia activa sobre los visitantes. Una vez analizado el tarjet y creado el producto, nos queda una tarea ardua y difícil, darnos visibilidad. Coincidimos con Molina en que «no importa el tamaño de una actividad cultural, un buen gestor debe buscar llevarla a los medios de comunicación, antes, durante y después de su realización, pues lo que no se comunica simplemente parece no existir» (2008, p. 18). De nada sirve tener un producto cuidado y de calidad si no es accesible al público por lo que debemos trabajar los canales de venta.

El primer paso es diseñar una página web moderna y visual, de fácil manejo tanto desde dispositivos móviles como ordenadores. Este es un punto crítico ya que las consultas por internet, desde el móvil, hoy día son superiores a los ordenadores, máxime en nuestro sector que implica movilidad residencial. La posibilidad de reservar online es una facilidad para el usuario, pero especialmente para el gestor, permitiendo organizar los recursos en función de la demanda.

Tabla 2

Estrategia activa sobre los visitantes

\begin{tabular}{ccc}
$\begin{array}{c}\text { Web moderna con sistema } \\
\text { de reservas online }\end{array}$ & $\begin{array}{c}\text { Acuerdos con agencias de } \\
\text { viajes y hoteles de la región }\end{array}$ & $\begin{array}{c}\text { Comunicación constante con } \\
\text { oficinas de turismo }\end{array}$ \\
$\begin{array}{c}\text { Presencia en medios y } \\
\text { directorios de viajes }\end{array}$ & $\begin{array}{c}\text { Contactar con asociaciones } \\
\text { culturales y centros }\end{array}$ & $\begin{array}{c}\text { Viralizar imágenes } \\
\text { de calidad }\end{array}$ \\
\hline
\end{tabular}

Fuente y elaboración propia

La primera línea de acción será ofrecer y entablar relaciones con agencias de viajes, especialmente las que tengan motivaciones culturales, para que puedan establecer rutas hacia nuestro destino. Del mismo modo, en el entorno próximo debemos colaborar con los hospedajes locales ya que serán un auténtico emisor de visitantes. Del mismo modo, las oficinas de turismo son puntos estratégicos de redistribución de excursionistas, razón que justifica una fluida relación que informe de nuestros servicios.

Es obvio el interés que tiene la repercusión de nuestras acciones en medios de comunicación, especialmente radio, prensa y televisión. Lógicamente no podemos ser siempre noticia en medios nacionales, pero alternativamente podemos tener presencia constante en medios locales. Para atraer la atención de los medios 
basta con organizar actividades, charlas y visitas especiales, cuyo contenido cultural justifica su presencia. También puede ser recomendable redactar nuestro propio blog ya que de este modo la información que queremos difundir no tendrá alteraciones en el mensaje. Por último, tener una buena reputación en directorios de viajes es una carta de presentación inmejorable, todavía más si cabe en nuestra propia web. Las recomendaciones de usuarios y visitantes dan testimonio real del interés de un destino.

Contactar con asociaciones culturales y centros cívicos siempre es una oportunidad para sumar excursiones de grupos organizados a nuestro destino. Con la finalidad de facilitar la tarea es conveniente hacer listados de direcciones de correo electrónico y visitar físicamente las instituciones culturales para depositar folletos informativos. Esta es una tarea que requiere mucho tiempo y constancia por lo que debe circunscribirse a un área próxima, origen de la mayor parte de nuestros visitantes o para paliar dicha deficiencia.

Por último nos gustaría remarcar el poder de la imagen en un mundo basado en la comunicación iconológica. La repercusión que puede alcanzar una fotografía en nuestros días no tiene precedentes, siendo un reclamo inmejorable para la acción turística. En esta tesitura abogamos por colaborar con profesionales de la imagen que depositen sus trabajos a la red, para que cada vez más gente conozca el patrimonio. Del mismo modo es conveniente animar y facilitar que los visitantes suban sus propias instantáneas a sus redes sociales.

\section{Herramientas para la fidelización de visitantes}

A priori nuestra propuesta cultural puede parecer poco proclive a la fidelización, siendo un consumo, el turístico, en muchas ocasiones de una sola ocasión. Sin embargo, nos sorprendió el renovado interés de los visitantes, repitiendo experiencia, y lo que es más, haciendo de anfitrión sobre familiares y amigos que desconocían el patrimonio.

A continuación reflejamos en la Tabla 3 los campos en que podemos operar para obtener la fidelización de visitantes a enclaves patrimoniales:

\section{Tabla 3}

Estrategia de fidelización

\begin{tabular}{cc}
\hline Atención personalizada & Promociones \\
Newsletter & Tarjeta de membrecía \\
\hline Fuente y elaboración propia &
\end{tabular}

Lo primordial es ofrecer una atención personalizada, ya sea vía telefónica, web o presencial. El concepto es que el visitante se sienta cómodo y escuchado, atendiendo sus observaciones ya que estas serán valiosas para conocer la percepción que tiene del servicio. En ocasiones es el propio usuario quien propone productos o servicios, simplemente es necesario estar receptivo. 
Las campañas de promoción ayudan a movilizar colectivos más sensibles al precio o que buscan nuevas experiencias. Supone un recurso útil emplear descuentos, sorteos en redes sociales o días temáticos para adquirir repercusión. Esta política es aconsejable en períodos de baja actividad. El gestor tiene el deber y la responsabilidad de acudir a eventos y charlas para dar a conocer el legado que administra, promocionando patrimonio y territorio de forma conjunta.

Aquellos visitantes satisfechos con su excursión es probable que quieran conocer información adicional, eventos, actividades o resultados de nuevas investigaciones. En esta línea, para mantener conectado al usuario con el patrimonio puede pedirse su correo electrónico para recibir notificaciones periódicas en una cadena newsletter. El uso de esta vía debe ser responsable y paulatino para no sobresaturarse de información.

Recompensar a los visitantes fieles, hacerles partícipes del proyecto y crear una pequeña comunidad de seguidores es algo tan sencillo como entregar tarjetas personalizadas. El mero hecho de entregar un carné de miembro es bien recibido ya que estás reconociendo a una persona en una institución cultural. Las ventajas de la membrecía pueden ser diversas tales como descuentos en la tienda, prioridad en los eventos, acceso a información, utilización de espacios, etc. El paso siguiente, si se logra establecer vínculos profundos, es la creación de una asociación de amigos, elemento común en los museos o un grupo de protección del patrimonio. El resultado final es convertir visitantes entusiastas en activos prescriptores e incluso defensores de la causa patrimonial.

\section{Crowdfunding, herramienta de financiación}

Un excelente instrumento de financiación si no contamos con otros medios o queremos complementar los disponibles es el micromecenazgo o crowdfunding. Término que proviene de la unión del anglicismo crowd (multitud) y funding (financiación). Se basa en las aportaciones de pequeños mecenas que depositan sus fondos a cambio de ciertas recompensas. Si el objetivo marcado es alcanzado el proyecto podrá hacerse realidad y los participantes se convertirán en parte activa de su éxito. Si el objetivo mínimo marcado no es sobrepasado, los mecenas que apoyaron la iniciativa no tendrán que hacer desembolso alguno y por ende, tampoco recibirán recompensas.

El concepto es el de una carrera de fondo (40 días normalmente) en busca de soporte financiero de sujetos individuales.

Además de hacer viables proyectos que de otra manera no serían posibles, «permite al promotor testear en el mercado tanto el producto o servicio con su potencial consumidor o usuario como el proyecto empresarial con su potencial inversor» (Gracia, 2014, p. 7). Por si estas razones no fueran suficientes, el crowdfunding es una excelente plataforma de publicidad y promoción. En el peor de los casos, si no se tiene éxito en la campaña de financiación al menos ha podido servir para dar a conocer nuestra existencia.

Existe en España múltiples ejemplos de proyectos de investigación arqueológica que han sido sufragados a partir de este canal: la necrópolis celtibérica de Checa (Guadalajara), San Miguel III (Huesca), el proyecto de prospecciones subacuáticas (Cabrera, 2013) y otros. Lo mismo puede decirse respecto a la difusión del 
patrimonio (digitalización de los libros sacramentales de Valls, Tarragona), puesta en valor y restauración (imagen de Mare de Déu del Patrocini de Cardona, Barcelona).

Antes de pasar a describir las fases y condiciones que requiere un exitoso crowdfunding, debemos advertir que este es un medio al que se debe recurrir en contadas ocasiones. No podemos alentar la colaboración ciudadana de forma reiterada, perdiendo el impacto inicial que logró que fuera atendida nuestra primera llamada a la participación. Por esta razón, debemos tener planificada y trabajada de antemano nuestra campaña, puede que sea una oportunidad única.

Fases del crowdfunding:
1. Proyecto
2. Presupuestos
3. Promoción de campaña
4. Captación de mecenas
5. Final

Figura 1. Esquema de las fases del crowdfunding.

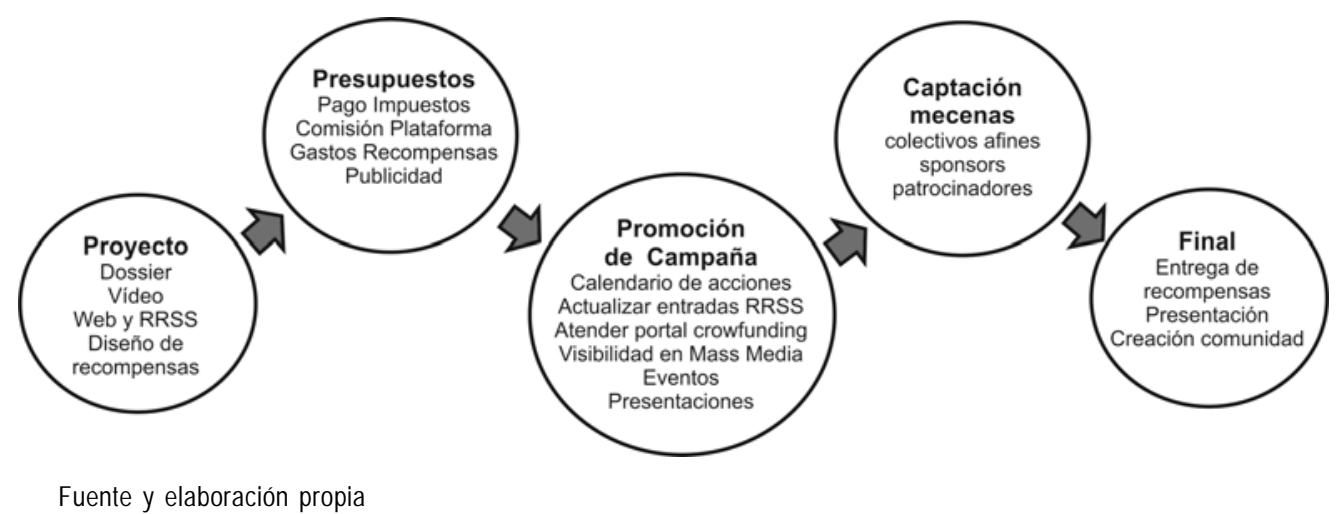

Es conveniente que previo a comenzar nuestra campaña de crowdfunding hayamos sentado las bases de nuestros canales de comunicación con las distintas audiencias. Para ello, abriremos nuestra propia web, perfil en redes sociales y Youtube, comenzando a subir contenido de nuestra iniciativa.

Una vez seleccionada la plataforma que vamos a utilizar para nuestra campaña, en función de un destinatario nacional o internacional, el primer paso será diseñar un proyecto coherente, atractivo que logre transmitir sus valores para ser compartidos. Es preciso elaborar un dossier descriptivo, visual y sencillo en el que figuren nuestros objetivos, necesidades, calendario, y que señale a qué van a ir dirigidas las aportaciones de los mecenas. 
Recomendable es grabar un video de pocos minutos que ilustre nuestra visión, una vía fácil de compartir en internet. Por último, diseñaremos las recompensas para los padrinos de nuestra propuesta; pueden ser productos o servicios afines que resulten tentadores para el público.

El cálculo de costes de producción de nuestro proyecto debe ir acompañado de otros gastos como la comisión de la plataforma de crowdfunding (+/- 5\%), tasas bancarias (+/- 3\%), IVA (21\%) y otros gastos imprevistos como desplazamientos y material publicitario.

La campaña de promoción solo debe iniciarse cuando exista una planificación previa y los canales de comunicación estén suficientemente maduros. La elección de la fecha de arranque no es una cuestión menor ya que debe hacerse en el momento apropiado para tener la atención máxima de la audiencia. Se desaconsejan períodos vacacionales, momento en que el público se desconecta de su entorno. Teniendo presente que una campaña de crowdfunding es un maratón de recaudación, con las mayores aportaciones al inicio y al final, estas fases deben cuidarse de forma especial.

Tener un calendario de actividades previstas de promoción es una buena política para evitar caer en la inercia e inactividad. De forma constante se debe interactuar con las redes sociales, actualizar el blog de la campaña con los progresos del proyecto y acudir a medios de comunicación como vía de publicitarse. Contamos con la ventaja actual de que el crowdfunding es aún un instrumento novedoso que capta la atención de la prensa. Esta misma característica es también una de sus principales desventajas ya que puede existir una barrera tecnológica frente a algunos colectivos que no están familiarizados con el método.

Figura 2. Gráfica con la evolución de la campaña de crowdfunding «Exposición Brujas de la Alcarria». En barras verticales las aportaciones por fecha y la línea blanca ascendente es la recaudación.

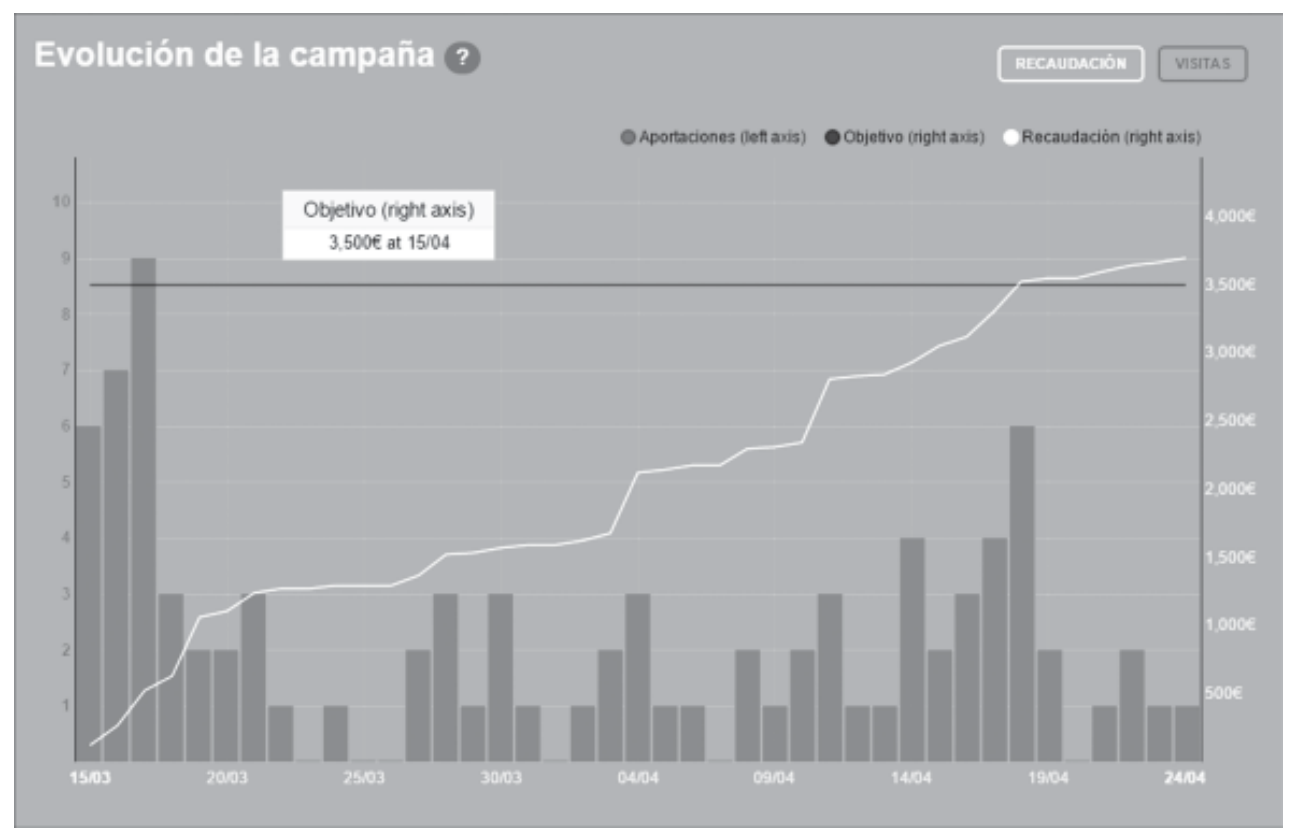

Fuente y elaboración propia 
Para sumar en la empresa que nos ocupa, es una táctica interesante acudir a presentar nuestro proyecto, considerando incluso la venta directa de las recompensas para todos aquellos que prefieran aportar de forma inmediata, siendo nosotros los interlocutores con la plataforma online. Del mismo modo, podemos organizar eventos que recauden fondos para la causa o merchandise a la venta de modo permanente.

Negociar con sponsors y patrocinadores locales puede ser muy beneficioso ya que estos son los principales interesados en que el ámbito patrimonial genere turismo. Los establecimientos orientados a la hostelería y servicios serán un fuerte aliado. En algunas ocasiones dicha colaboración puede ser en especies en vez de metálico, una baza siempre más sencilla de obtener y que puede darnos igualmente grandes réditos.

El último paso en muchas campañas de crowdfunding significa la producción y entrega de las recompensas, inauguración del proyecto y agradecimientos. Este procedimiento cierra una relación iniciada con los mecenas, expulsando a los artífices del proyecto una vez conseguido. La creación de una comunidad de apoyo debería ser el inicio de otra etapa del proyecto, contando con la presencia de un grupo de inversores que creyeron en ello. La comunicación a través de los canales forjados durante el proceso puede ser empleada de forma indefinida posteriormente.

\section{Conclusiones}

Se pretende facilitar estrategias de viabilidad en la gestión del patrimonio histórico basándonos en nuestra propia experiencia de campo. Estas recetas han sido testadas en un entorno rural en dos centros históricos que no contaban con respaldo financiero público, razón que motivó la búsqueda de otras vías de financiación. Los resultados han sido muy alentadores, fruto de un intenso trabajo dirigido por la figura de un gestor cultural profesional. Por este motivo, defendemos la presencia de este perfil en enclaves patrimoniales, si de verdad se pretende que se conviertan en motores de desarrollo local.

En la actualidad, comprendemos que debemos actuar en sintonía con la investigación científica para que conocimiento e interpretación vayan en una sola dirección, una tónica no siempre sencilla. La accesibilidad al público de nuestro legado repercutirá en mayor interés por la ciencia, lo cual permitirá crear un conocimiento de calidad, lejos de visiones estereotipadas.

En definitiva, se defiende la apuesta por el patrimonio, sea de cualquier naturaleza, como un recurso potencialmente rentable, tanto a nivel social como económico. La administración como custodia de dicho legado debe facilitar las herramientas para el disfrute y conservación del mismo, atendiendo a colaborar con entes públicos y privados. 


\section{Referencias}

Almenar, P. (13 de agosto de 2014). El Museo Nacional de Cerámica deja de abrir de noche por falta de presupuesto. El País. Recuperado de http://ccaa.elpais.com/ccaa/2014/08/12/valencia/1407862134_404002.html

Associació de Professionals de la Gestió Cultural de Catalunya (2011). Guía de Bones Pràctiques de la Gestió Cultural. Barcelona: APGCC.

Calleja, A. (7 de enero de 2014). El Museo Arqueológico, sin viso de solución. Granadaimedia. Recuperado de http://granadaimedia.com/ cierre-museo-arqueologico-granada/

Casacuberta, D. (2008). Industrias culturales basadas en redes distribuidas. Washington, DC: Banco Interamericano de Desarrollo, Fondo Multilateral de Inversiones.

Consejería de Cultura de la Junta de Andalucía - Dirección General de Bienes Culturales (2009). Plan director del conjunto arqueológico de Carmona. Dirección técnica Ignacio Rodríguez Temiño.

Consejería de Cultura de la Junta de Andalucía. Dirección General de Bienes Culturales (2009). Plan director del conjunto arqueológico de Itálica (Documento de avance 2009). Red de espacios culturales de Andalucía.

Criado-Boado, F. (1996). Hacia un modelo integrado de investigación y gestión del Patrimonio Histórico: la cadena interpretativa como propuesta. Instituto Andaluz del Patrimonio Histórico. Boletín del Instituto Andaluz del Patrimonio Histórico, $16,73-78$.

Soria, J. M. (17 de agosto de 2014). Los turistas lanzan críticas al descuido del yacimiento de Numancia. Diario de Soria. Recuperado de http://www.diariodesoria.es/noticias/soria/turistas-lanzan-criticas-descuido-yacimiento-numancia_25118.html

El Correo de Andalucía (19 de mayo de 2016). La falta de personal obliga a cerrar parte de Itálica. El Correo de Andalucía. Recuperado de http://elcorreoweb.es/provincia/la-falta-de-personal-obliga-a-cerrar-parte-de-italica-LI1794379

Fernández, J. (2017). Gestión privada del patrimonio cultural: Los casos del monasterio de Monsalud y la ciudad romana de Ercávica. Pasos revista de Turismo y Patrimonio Cultural, 15(1), 121-137.

García, M. P. (2012). El patrimonio cultural. Conceptos básicos. Zaragoza: Prensas universitarias de Zaragoza.

Gracia, C. (2014). Presente y futuro del crowdfunding como fuente de financiación de proyectos empresariales. Revista Española de Capital Riesgo, 1, 3-19.

Hiernaux, N. (mayo, 2011). Patrimonio y turismo: Discutiendo la noción de «aura» en la mundialización. Ponencia en el Encuentro Iberoamericano de Gestión del Patrimonio, UAM Xochimilco. Recuperado de http://www.danielhiernaux.net/publicaciones/ index2.php

Instituto de Estudios Turísticos IET (2007). Informe de hábitos turísticos de los residentes en España. Madrid: Ministerio de Industria, Turismo y Comercio.

Las Noticias de Cuenca (10 de mayo de 2016). La Diputación mantendrá la gestión de Segóbriga si la Junta asume las pérdidas. Las Noticias de Cuenca. Recuperado de http://www.eldiario.es/clm/Diputacion-mantendra-Segobriga-Junta-perdidas_0_514449419.html

López de Calle, C., \& Tudanca, J. M. (2006). El patrimonio cultural estratigrafía razonada de un concepto. Berceo, 151, 11-29.

Martinell, A. (2007). La gestión cultural singularidad profesional y perspectivas de futuro. Trabajo presentado en el seminario internacional: La formación en gestión y políticas culturales para la diversidad cultural y el desarrollo. Girona.

Mayer, C. (26 de agosto de 2016). Cierra el Museo de Historia de Madrid porque el Ayuntamiento no ha renovado a tiempo al personal. Libertad Digital. http://www.libertaddigital.com/espana/2016-08-26/cierra-el-museo-de-historia-de-madrid-porque-elayuntamiento-no-ha-renovado-a-tiempo-al-personal-1276581227/

Molina, L. E. (2008). Gestión Cultural: Comunicación, Publicidad, Conservación y el uso de las Redes Sociales y la web 2.0 desde el enfoque de la Gestión Cultural. Ministerio de Cultura de la Republica Dominicana.

Muñoz, F. (2005). En torno al «Grand Tour». Análisis de un caso paradigmático. Contribuciones a la Economía. Recuperado de http:/ /www.eumed.net/ce/ 
Organización para la Cooperación y Desarrollo Económicos - OCDE (1988). Nuevas tendencias en política rural. Madrid: ITUR, MOPU.

Organización Mundial del Turismo (2013). Manual de desarrollo de productos turísticos. Madrid: OMT.

Pérez, E., \& Chávez, M. E. (2012). El papel del patrimonio arqueológico en el turismo de las Islas Canarias. Trabajo presentado en el I Congreso Internacional El patrimonio cultural y natural como motor de desarrollo: investigación e innovación, 1725-1732.

Prats, L. (1997). Antropología y Patrimonio. Barcelona: Ariel.

Querol, M. A. (2010). Manual de gestión del patrimonio cultural. Madrid: Akal.

Rowan, J. (2010). Emprendizajes en cultura: discursos, instituciones y contradicciones de la empresarialidad cultural. Barcelona: Traficantes de sueños.

Sandri, P. (6 de junio de 2014). Turismo arqueológico en España. La Vanguardia. Recuperado de http://www.lavanguardia.com/estilosde-vida/20140606/54408757180/turismo-arqueologico-en-espana.html

Sancho, J. \& Reinoso, J. D. (2012). La delimitación del ámbito rural: una cuestión clave en los programas de desarrollo rural. Estudios Geográficos, 73(273), 599-624.

Sostenuto (2012). La cultura como factor de innovación económica y social. Valencia: Economía de la Cultura y Turismo (ECONCULT).

Traverso, J. (1996). Comunicación interpretativa: variable clave en el marketing-mix de las empresas de turismo rural. Estudios Turísticos, 130, 37-50.

Velasco, M. (2013). Conceptos en evolución turismo, cultura y turismo cultural. En J. I. Pulido \& M. C. Vaquero (Coord.), Turismo cultural (pp. 15-46). Madrid: Síntesis. 